\title{
TERRITÓRIO EM DISPUTA NO LITORAL CEARENSE: A RESISTÊNCIA/INOVAÇÃO DO TURISMO COMUNITÁRIO DIANTE DAS AÇÕES E CONTRADIÇÕES DO ESTADO*
}

\author{
Lenilton Francisco de Assis* \\ Centro de Educação da UFPB
}

Resumo: O litoral cearense do Nordeste brasileiro já registra várias experiências exitosas de turismo comunitário. Porém, o governo do estado continua preterindo esse potencial e subsidiando a instalação de megaempreendimentos que geram poucos empregos com baixas remunerações. Assim, as comunidades litorâneas que protagonizam o turismo comunitário ficam duplamente penalizadas, pois são deixadas à margem das políticas de turismo e seus territórios viram alvos da cobiça de visitantes atraídos pelo marketing dos investimentos públicos realizados. Tomando como estudo de caso a comunidade de Tatajuba, no município de Camocim, no Ceará, este artigo analisa a luta dos povos do mar pelo território luta essa que não se traduz apenas na defesa do espaço de vivência, mas também na formação de uma rede de territórios solidários articulados ao mundo, que resiste/inova com a proposta do turismo comunitário.

Palavras-chave: Turismo. Território. Turismo comunitário. Geografia do turismo. Tatajuba.

DISPUTED TERRITORY ON THE COAST OF CEARÁ: THE STRENGTH AND INNOVATION OF COMMUNITY TOURISM ON THE ACTIONS AND CONTRADICTIONS OF STATE

Abstract: The cearense coast of Northeastern Brazil already registers several successful experiences of Community tourism. However, the state government is still neglecting this potential and subsidizing the installation of mega-enterprises that generate few jobs with low pay. Thus, the coastal communities who star the community tourism are doubly penalized because they are abandoned by tourism policies and their territories become targets of greed of visitors attracted by the marketing of public investments. Taking as a case study the community of Tatajuba, in Camocim (municipality, Ceará, Brazil), this article examines the struggle of the peoples of the sea through the territory. This fight not only translates on defense of the living space, but also it represents the formation of a worldwide network of solidary territories that resists and innovates with the proposal of community tourism.

Keywords: Tourism. Territory. Community tourism. Tourism geography. Tatajuba.

DISPUTA DE TERRITÓRIO EN LA COSTA DE CEARÁ: LA FUERZA/INNOVACIÓN DEL TURISMO COMUNITÁRIO SOBRE LAS ACCIONES Y LAS CONTRADICCIONES DEL ESTADO

Resumen: El turismo comunitario ya registra varias experiencias exitosas em la costa de Ceará en el noreste de Brasil. Sin embargo, el gobierno del estado continúa pasando por encima de este potencial y subvencionando la instalación de mega-empresas que generan pocos empleos con bajos salarios. Por lo tanto, las comunidades costeras que ofrecen el turismo comunitario son doblemente penalizadas porque quedan excluidas de las políticas de turismo y sus territorios se convierten en objeto de la codicia de los visitantes atraídos por la comercialización de las inversiones públicas. Tomando como caso de estudio la comunidad Tatajuba, en el municipio de Camocim, este artículo examina la lucha de los pueblos del mar por el territorio, lucha que no sólo se traduce en la defensa del espacio de vida, sino también en la formación de una red de territorios articulado con el mundo que resiste e innova con la propuesta del turismo comunitario.

Palabras clave: Turismo. Territorio. Turismo comunitario. Geografia del turismo. Tatajuba.

*Artigo adaptado e ampliado da pesquisa de doutorado do autor (ASSIS, 2012)

${ }^{*}$ Geógrafo, doutor em Geografia Humana pela USP, professor doutor do Centro de Educação da UFPB, Departamento de Metodologia da Educação - DME, Programa de Pós-Graduação em Geografia - PPGG. Endereço profissional: Cidade Universitária, s/n, Castelo Branco, João Pessoa/PB - Brasil. Departamento de Metodologia da Educação, Centro de Educação, Campus I, UFPB. CEP. 58051900. E-mail: lenilton@yahoo.com 


\section{Introdução}

O litoral cearense possui $573 \mathrm{~km}$ de praias rodeadas por dunas, falésias e mangues que, se por um lado maravilham os visitantes com extensas áreas desertas e semi-habitadas, por outro têm muitos dos seus encantos quebrados com a dura realidade das comunidades tradicionais cuja sobrevivência advém da pesca e da agricultura. Sempre acolhedoras com os turistas, essas comunidades não recebem o devido apoio do Estado para explorar a natureza que lhes foi tão pródiga e que elas têm sabido perpetuar.
Ainda assim, as comunidades litorâneas do Ceará protagonizam iniciativas solidárias com o turismo comunitário no qual os próprios moradores são responsáveis pela oferta dos meios de hospedagem, a alimentação e o lazer dos visitantes. Essas experiências vêm sendo reconhecidas por parceiros (como universidades, organizações não governamentais ONGs e instituições estrangeiras), que criaram a Rede Cearense de Turismo Comunitário - a rede Tucum (Figura 1).

FIGURA 1 - REDE CEARENSE DE TURISMO COMUNITÁRIO

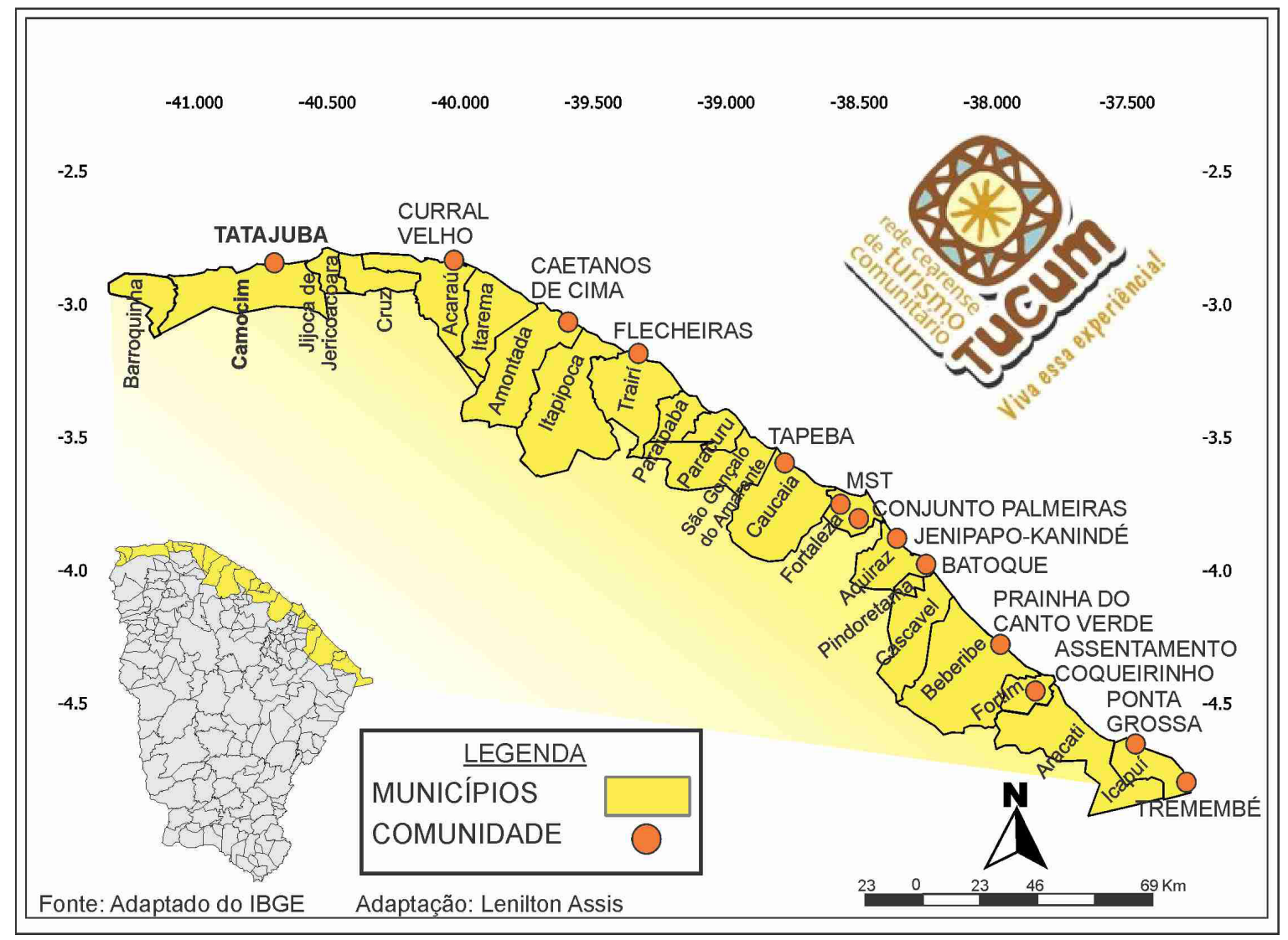

No roteiro da rede Tucum está associado o que há de mais rico no produto turístico do Ceará - a diversidade das suas paisagens e a cultura do seu povo. Todavia, essa riqueza ainda é pouco explorada devido à visão do Estado de só enxergar nos grandes empreendimentos a capacidade de converter o enorme potencial turístico em mais oportunidades de emprego e renda para a população.

Essa opção de gestão incorre numa falácia que ignora as iniciativas endógenas existentes, inferioriza as comunidades tradicionais, tirando delas o direito de serem também "empreendedoras" do seu futuro - por que não?
Preteridasnasações governamentais, ascomunidades passam a vivenciar no cotidiano uma disputa acirrada pelo território diante das investidas de empresários e turistas estrangeiros que aportam no litoral do Ceará com o interesse de instalar empreendimentos imobiliárioturísticos (hotéis, resorts, condoresorts, parques temáticos etc.), que logo atraem a atenção do Estado. Em muitos casos, os megaempreendimentos alardeados como panaceia desenvolvimentista convertem-se em projetos turísticos de "fachada" que ocultam reais interesses imobiliários de especular as terras litorâneas, desterritorializar as comunidades e promover vendas futuras no mercado internacional. 
Assim, as ações do Estado são portadoras de contradições que reforçam a fragmentação do território, o aumento das desigualdades socioespaciais, já que as políticas e os investimentos públicos adotam a mesma lógica excludente do mercado, de priorizar agentes e espaços que já são competitivos.

Ora, o papel esperado do Estado é o de contrabalançar, com sua presença, a relativa ausência de investimentos privados. E não de concentrar-se onde o ente privado já prefere se localizar, onde o dinamismo conduzido pela lógica do mercado já é mais intenso, onde os novos fatores de competitividade já são abundantes. A preocupação que daí deriva é sobre o destino das chamadas áreas "não competitivas". (ARAÚJO, 2000, p. 229)

A adoção dessa lógica seletiva nas políticas de turismo acirra a luta pelo território no litoral cearense, aumentando, por conseguinte, os movimentos de resistências das comunidades, já que estas não existem sem seus territórios. A perda do território é, de maneira geral, o fim das comunidades e dos seus sujeitos, pois, como nos lembra Haesbaert (2006, p. 20), "não há como definir o indivíduo, o grupo, a comunidade, a sociedade sem ao menos inseri-los num determinado contexto geográfico, 'territorial'". Esse é o fulcro em que se sustenta a luta dos povos do mar pelo território, luta essa que adquire um sentido supremo e cuja causa é partilhada por indígenas e camponeses que se associam na rede Tucum formando uma rede de territórios solidários, articulados ao mundo, que resistem e inovam com a proposta do turismo comunitário.

Secundário no âmbito das políticas públicas, o turismo comunitário' ${ }^{1}$ ganhou a atenção dos estudiosos acadêmicos, no Brasil, sobretudo a partir de 1997, nas várias edições do Encontro Nacional de Turismo de Base Local (ENTBL). A possibilidade de o turismo comunitário promover o desenvolvimento local foi um dos chamativos para muitos pesquisadores darem visibilidade às experiências que se difundiam no País, em especial no litoral cearense.

O protagonismo do Ceará, inclusive, levou o estado a sediar a segunda edição do ENTBL, em 1998, assim como o I e o II Seminário Internacional de Turismo Sustentável (SITS) em 2003 e 2008. O II SITS se tornou um marco do turismo comunitário no País por ter reunido pesquisadores, instituições governamentais e não governamentais que pactuaram uma agenda de ações que resultou, ainda em 2008, no lançamento do I Edital de Chamada Pública de Projetos de Apoio ao Turismo de Base Comunitária. Nesse documento, o Ministério do Turismo (MTur) define o turismo de base comunitária

'Também designado Turismo de Base Comunitária (TBC), tanto na literatura acadêmica quanto na esfera governamental. como:

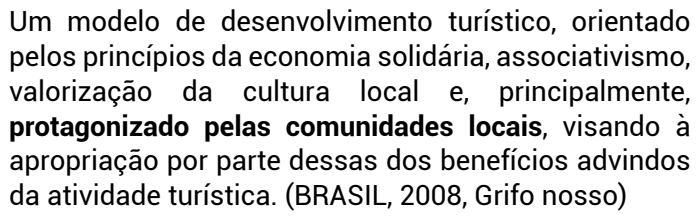

O edital superou as expectativas do MTur, que esperava acolher entre 100 e 150 propostas e foi surpreendido com mais de 500 projetos oriundos de todas as unidades da Federação. Desses, 50 projetos foram aprovados para execução entre 2008 e 2009. O Ceará e o Rio de Janeiro encabeçaram a lista dos estados com maior número de aprovações, cada um com seis projetos.

O número significativo de propostas demonstrava a diversidade de experiências do turismo comunitário no País (BRASIL, 2010) e o apelo das comunidades por políticas de turismo que, realmente, invertessem a lógica excludente das suas ações: em vez de focalizar no atendimento dos anseios dos turistas, deveriam priorizar as necessidades das comunidades receptoras.

É claro que essa inversão, há muito defendida por estudiosos e importantes organizações não governamentais ${ }^{2}$, ecoou nas políticas federais de turismo, não só pela maior abertura do governo do Partido dos Trabalhadores ${ }^{3}$, mas sobretudo pela pressão das comunidades que já acumulavam experiências variadas com o turismo comunitário.

0 edital do MTur e seu reconhecimento às necessidades de protagonismo e empoderamento político das comunidades foram conquistas significativas a comemorar. E, novamente, o Ceará foi pioneiro nesses levantes, tendo no Batoque (Aquiraz) e na Prainha do Canto Verde (Beberibe) movimentos em defesa da pesca e do turismo comunitário que repercutiram no País e no mundo. Nessas praias, a luta das comunidades resultou na criação, pelo governo federal, das duas primeiras reservas extrativistas do Ceará.

No bojo dessas ações e da apatia do governo do estado para fortalecer a política federal em prol do turismo comunitário, foi criada, em $2008^{4}$, a rede Tucum,

\footnotetext{
${ }^{2}$ A exemplo da Organização Mundial de Turismo (OMT), que, em 1999, aprovou o Código de Ética Mundial para o Turismo, no qual defende o turismo responsável e sustentável, baseado na participação equitativa das populações e comunidades locais nos benefícios econômicos, sociais e culturais do turismo. Outra ONG internacional importante é o Fundo Mundial para Vida Selvagem (WWF) que, em 2003, cunhou o conceito de "ecoturismo de base comunitária", ratificando os princípios éticos do turismo.

IIniciado em 2003, com o primeiro mandato do presidente Lula, o qual criou o Ministério do Turismo e lançou o Plano Nacional de Turismo 2003-2007. Todavia, até o Edital de Chamada de Projetos, já no segundo mandato, em 2008, o governo Lula teve apenas ações pontuais de apoio ao turismo de base comunitária, como sinalizam Silva, Teixeira e Ramiro (2009).

${ }^{4} \mathrm{~A}$ oficialização da rede Tucum também aconteceu no II Seminário Internacional de Turismo Sustentável, ocorrido em Fortaleza, em 2008.
} 
sob a mediação do Instituto Terramar ${ }^{5}$. Primeira rede estadual de turismo comunitário do Brasil, a Tucum conta com a participação de treze comunidades costeiras de pescadores, indígenas e de assentados rurais (Figura 1) que buscam criar estratégias de desenvolvimento pautadas na justiça ambiental, através da valorização da natureza, sociedade e cultura local.

Apropriando-se, em parte, dos sistemas técnicoinformacionais do presente, as comunidades da rede Tucum elaboram iniciativas coletivas para se contrapor às redes convencionais do turismo globalizado. Ao se associar a outras redes de maior dimensão, como a Rede Brasileira de Turismo Comunitário e Solidário (Turisol) e a Rede de Turismo Comunitário da América Latina (Redturs), a rede Tucum forma uma "rede de redes" ou um território-rede ${ }^{6}$ resultante da articulação e da solidariedade de "territórios-zona de resistência/ inovação", denominados por Adyr Rodrigues como aqueles não capturados pelo processo de globalização que tem na expansão mundial do turismo uma das suas principais formas de manifestação.

\begin{abstract}
São prioritariamente territórios de abrigo e recurso, prenhes de simbologia, onde predominam as relações de poder local marcadas por forte endogenia, ancoradas nos princípios de liberdade e autonomia. [...] São intertecidos pelas representações sociais que urdem valores, crenças, expectativas; modos de pensar, agir e sentir, que criam laços identitários elos interpessoais e das pessoas com o lugar, donde emana o sentido de pertencimento que vai construir a chamada consciência territorial. (RODRIGUES, 2008, p. 44-45)
\end{abstract}

Mesmo passíveis de conflitos e de clivagens internas, são dos laços e da consciência sobre o território (pela maioria) que nasce a resistência à sua apropriação por atores exógenos que possam impor uma lógica diferente daquela vivenciada. Como não há melhor forma de defesa do que $o$ ataque, as comunidades da rede Tucum não só resistem nos territórios-zona, mas também inovam, apresentando um modelo de turismo mais solidário, baseado em sinergias locais que envolvem diversos segmentos sociais e geram maior distribuição dos benefícios.
A comunidade de Tatajuba, em Camocim (Figura 1), é um dos exemplos cearenses de território insubordinado aos ditames do turismo global que analisaremos neste artigo. Embora seus moradores não estejam alheios ao mundo e suas inovações, na esfera local, onde a vida é regida por outros tempos e valores, eles defendem, para os nativos, a partilha coletiva do território e a autonomia da comunidade para gerir o espaço de vivência ocupado há mais de um século.

\section{Tatajuba: território-zona de resistência/inovação}

Tatajuba é uma comunidade de pescadores do município de Camocim, no Ceará, que se situa a aproximadamente $25 \mathrm{~km}$ da sede e a $340 \mathrm{~km}$ de Fortaleza. Ali a natureza sempre foi protagonista da dinâmica das paisagens que são marcadas por campos de dunas ${ }^{7}$, praias desertas, lagos costeiros, coqueirais, manguezais e ventos fortes. 0 território em disputa é formado por areias em movimento e em crescente valorização imobiliária.

Alheias aos embates, as areias teimam em mudar de lugar, jogando no rosto de moradores e visitantes sua força que já foi responsável pelo soterramento de casas e da igreja da Velha Tatajuba. Este evento forçou a reterritorialização da comunidade em quatro vilas que ficaram geograficamente separadas pelas dunas e gamboa ${ }^{8}$, mas unidas pela forte identidade da população com aquele território.

As vilas da Nova Tatajuba, São Francisco, Baixa da Tatajuba e Vila Nova formam a comunidade da Tatajuba que se localiza na porção leste do município de Camocim, próxima à famosa praia de Jericoacoara (Figuras 2 e 3 ). Jeri, como é carinhosamente apelidada, ficou conhecida internacionalmente após ter sido apontada como um dos dez lugares mais belos do mundo pelo jornal norteamericano The Washington Post, em 15 de março de 1987. Atualmente Jeri tem o pôr do Sol mais disputado do Ceará e apresenta uma diversificada rede de hospedagem e de serviços turísticos com hotéis, pousadas, casas de câmbio, agências de viagem, associação de bugueiros, restaurantes, bares e boates com várias opções de entretenimento e gastronomia.

${ }^{7}$ Formam-se ao longo da faixa litorânea a partir da deposição contínua de partículas de areia de praia transportadas pelos ventos. No Nordeste brasileiro, os campos de dunas propiciam morfologias diferenciadas que se associam à formação de terraços marinhos, lagoas costeiras, estuários e praias.

${ }^{8}$ Braço de mar que adentra ao continente no afluxo da maré propiciando o surgimento do manguezal pelo encontro de águas doce e salgada que formam um berçário natural para várias espécies de peixes, crustáceos e moluscos. 

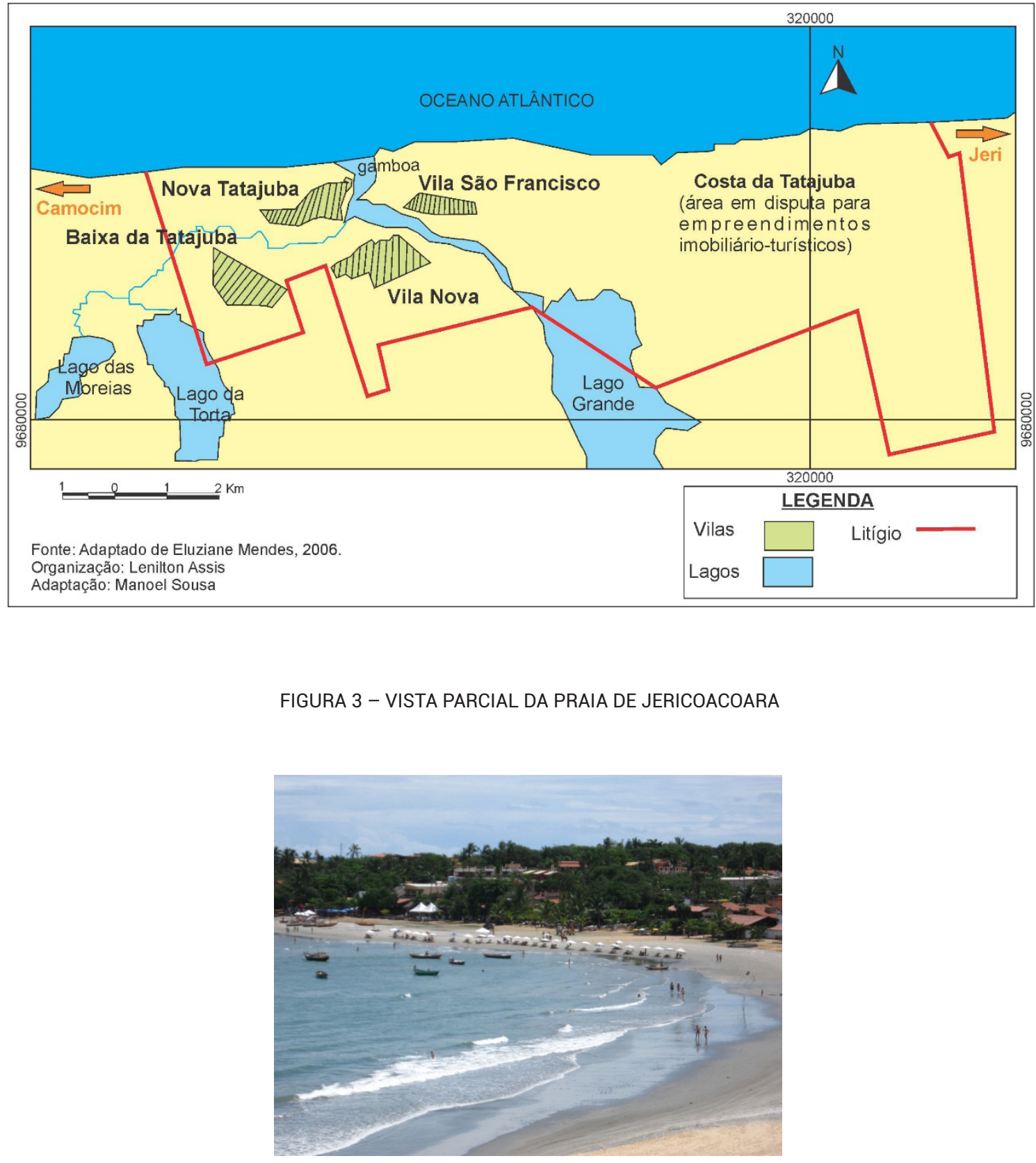

Fonte: Lenilton Assis, 2011

O fato de ser um lugar de passagem entre a praia de Jericoacoara $(30 \mathrm{~km})$ e a cidade de Camocim $(25 \mathrm{~km})$ faz com que Tatajuba vivencie, nas últimas décadas, uma forte especulação do seu território. Uma espécie de "tirania da proximidade" se instala na comunidade a reboque do crescimento de Jeri e do surgimento de grandes projetos imobiliário-turísticos em Camocim e região.
A comunidade conta com cerca de 1.000 habitantes distribuídos nas quatro vilas, em aproximadamente 200 habitações. A Nova Tatajuba (ou simplesmente Tatajuba, como é mais conhecida) é a vila central onde ficam instalados os principais equipamentos e serviços públicos (Figura 4). 


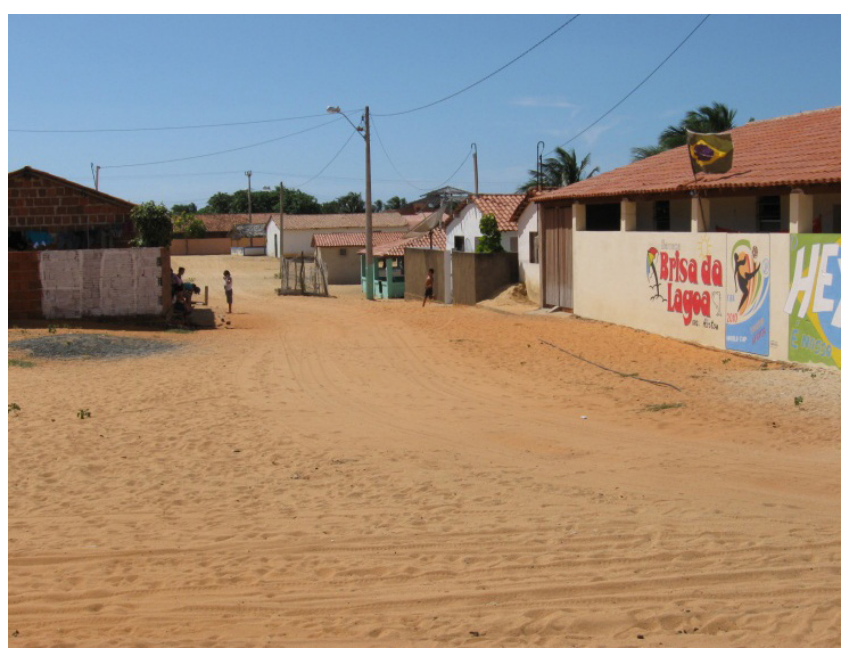

Fonte: Lenilton Assis, 2011

O grande potencial turístico local, antes de ser descoberto pelos "de fora", já era conhecido pelos moradores de Tatajuba, que, diariamente, convivem com turistas de Jeri que passam pela vila, especialmente com destino à lagoa da Torta ${ }^{9}$, onde barracas com mesas e redes dentro d'água servem de deleite (Figura 5).

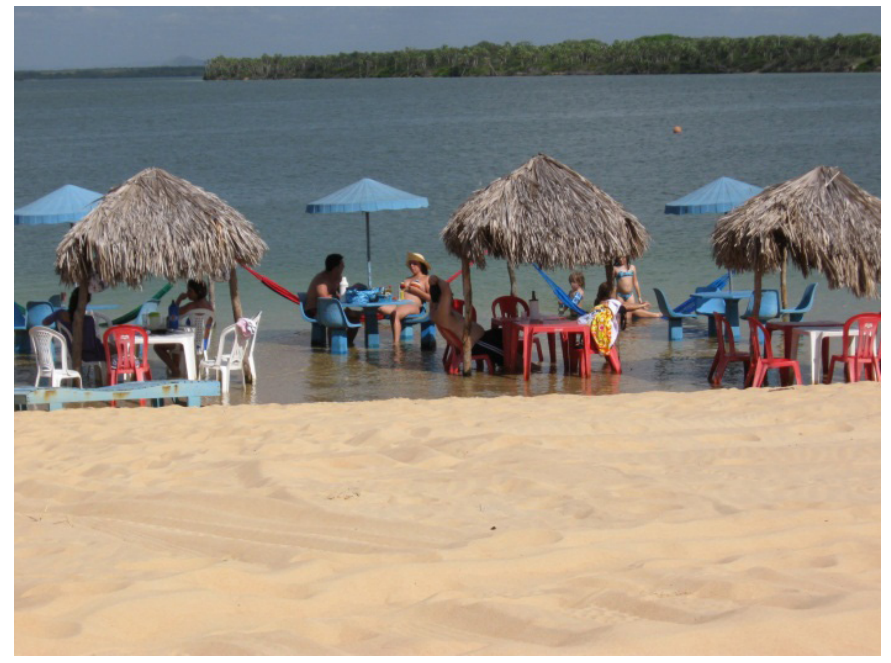

Fonte: Lenilton Assis, 2011.

${ }^{9}$ Também conhecida como laguinho da Torta ou lagoa de Tatajuba, é formada po água doce das chuvas que se acumulam, de modo intermitente, nas depressões interdunares. Devido às variações hídricas sazonais, a lagoa chega a secar e também a se mover à mercê da dinâmica das dunas. A lagoa serve de refúgio para fauna e de preservação para a flora, influenciando o microclima local e servindo de opção de lazer para moradores e visitantes. 
Os efeitos danosos do "turismo de massas de Jeri" (expressão usada por muitos nativos da comunidade) passaram a ser repudiados em Tatajuba na tentativa de evitar os seguintes problemas: especulação imobiliária, prostituição, consumo de drogas, concentração de renda nas mãos dos "de fora", aumento do custo de vida para os nativos e a degradação dos ecossistemas locais.

A criação da Associação Comunitária de Moradores de Tatajuba (Acomota), em 1991, foi o primeiro passo para que os nativos somassem forças com ONGs, universidades, órgãos públicos e outras comunidades já organizadas do litoral cearense para debater as potencialidades do turismo comunitário e promover o desenvolvimento territorial. Como bem afirma Araújo (2008, p. 26), "é muito mais fácil fazer desenvolvimento territorial quando ele é aplicado a um lugar onde a sociedade está organizada. Está estruturada. Sabe para onde quer ir. Sabe se articular".

Nesse sentido, o turismo comunitário requer o envolvimento da população no planejamento e no gerenciamento da atividade, sendo direcionado aos viajantes que buscam maior contato com o ambiente e a cultura local através da conservação dos ecossistemas e da valorização dos gêneros de vida da comunidade (RODRIGUES, 2008; CORIOLANO, 2009).

O turismo comunitário busca a autogestão dos recursos patrimoniais do território como estratégia de sustentabilidade que possa lograr o crescimento econômico, a conservação dos atrativos naturais e a distribuição mais equitativa de emprego e renda. Sobre esta modalidade de gestão do turismo, Irving (2009, p. 111) se pronuncia:

Considerando que o turismo, em qualquer de suas formas de expressão e intervenção, interfere na dinâmica socioambiental de qualquer destino, o turismo de base comunitária só poderá ser desenvolvido se os protagonistas deste destino forem sujeitos e não objetos do processo. Neste caso, o sentido de comunitário transcende a perspectiva clássica das "comunidades de baixa renda" ou "comunidades tradicionais" para alcançar o sentido de comum, de coletivo. [...] Este tipo de turismo representa, portanto, a interpretação "local" do turismo, frente às projeções de demandas e de cenários do grupo social do destino, tendo como pano de fundo a dinâmica do mundo globalizado, mas não as imposições da globalização.

Por meio de oficinas, cursos e capacitações promovidas pela Acomota, a comunidade de Tatajuba logo se apoderou da filosofia do turismo comunitário como principal bandeira de luta e resistência em defesa do território. De forma participativa, foi feito um diagnóstico da área com o indicativo das potencialidades e dos problemas que pudessem fomentar a elaboração de projetos e ações. Dessa iniciativa resultaram algumas conquistas como a instalação de energia elétrica, telefone comunitário, projeto de plantação irrigada de coqueiros e uma oficina de Turismo Sustentável, realizada em 1996 (TERRAMAR, 2008).

O combate à especulação imobiliária e a defesa do turismo comunitário se tornaram as molas mestras das ações da Acomota, as causas que uniram a comunidade, já que a venda de terras iniciada nos anos de 1970 intensificava-se na década de $1990 \mathrm{com}$ a valorização turística de Tatajuba que até então era considerada um "território de reserva" e de expansão de Jeri.

A comunidade de Tatajuba passou a se "fechar" e a defender a partilha coletiva do território para os nativos. Vale frisar que esse relativo fechamento foi imposto à comunidade e converteu-se na sua principal forma de luta pelo território e pela preservação de seus pressupostos identitários, diferenciando-se da lógica dos grupos hegemônicos que, muitas vezes, em nome da insegurança, optam pela segregação em pontos densamente articulados por redes, onde criam territórios "exclusivistas" e apartados do entorno - como ocorre nos resorts.

A defesa do território secularmente ocupado pelos antepassados serve como garantia de sobrevivência para as gerações futuras. Tarefa árdua essa, quando o território em questão é dotado de atrativos naturais paradisíacos que o convertem em mercadoria de grande disputa no ascendente mercado do turismo mundial.

Os embates em Tatajuba se iniciavam, pois promotores imobiliários da região demarcaram terras na comunidade dizendo tê-las comprado de nativos. A estratégia de "grilagem", já conhecida e praticada em todo o litoral, efetuava-se com a aquisição, a preços insignificantes, de lotes distantes da praia que, posteriormente, eram aumentados em direção ao mar, incorporando terras de uso da comunidade. A compra de coqueiros foi outra prática corriqueira dos "grileiros" para demarcar terrenos que logo eram ilegalmente registrados nos cartórios da região e revendidos a turistas estrangeiros e empresas nacionais (TERRAMAR, 2008).

Na década de 1990, o crescimento de Jeri fez com que a especulação imobiliária se difundisse em Tatajuba, levando a comunidade a sofrer constantes repressões que acirraram a luta pelo território e amedrontaram as famílias. Falsas promessas e o aliciamento de lideranças terminaram "quebrando" a coesão interna.

A comunidade antes representada apenas pela Acomota passou a ter mais duas entidades: o Conselho de Desenvolvimento Comunitário de Tatajuba e a Associação dos Moradores Rurais de Vila Nova e Adjacências. Ambas as instituições foram formadas 
por dissidentes da Acomota que adotaram discursos "conciliatórios" e coniventes com os empresários cujos interesses imobiliário-turísticos eram mascarados com a oferta de trabalhos informais a alguns moradores, doações de cestas básicas e patrocínio de projetos (como o coral infantil, oficinas de artesanato e horta comunitária) que, em médio prazo, cessaram com a venda das terras a novos especuladores.

A disputa e o dinheiro passaram a "correr soltos" em Tatajuba, criando rivalidades entre as famílias que fragmentaram a comunidade. As quatro vilas que representavam uma única jurisdição em Tatajuba foram sobrepostas, invadidas e culturalmente separadas por atores externos que agem em redes articuladas de poder e impõem outra lógica e tessitura ao território.

Novos atores aportaram em um territóriozona naturalmente apartado pelas dunas e marés para comprar e especular a terra. Velhos atores se transformaram. Uns, eivados da consciência política e territorial, prosseguiram na luta como forma de sobrevivência. Outros se aproveitaram dessa situação como oportunidade de subir na vida, alheios aos laços e às tradições seculares com a terra e o seu povo.

Entre 2000 e 2003, os conflitos se acentuaram, deflagrando um período crítico de luta que teve como estopins duas ações da Vitória Régia descobertas pela Acomota: o projeto de construir o empreendimento "Condado Ecológico de Camocim"; e os registros cartoriais da empresa, datados de junho de 1993, que atestavam a propriedade de $5.275,450$ hectares de toda a área habitada pela comunidade.

De imediato, tais descobertas levaram a Acomota a tomar uma série de medidas, dentre as quais se destacaram duas ações impetradas na justiça de interdito proibitório e de anulação dos registros de terra da Empresa Vitória Régia ${ }^{10}$.

O laudo ambiental do Instituto Brasileiro do Meio Ambiente (BRASIL, 2001) foi o primeiro diagnóstico oficial da comunidade que serviu como fulcro de acirramento da luta e resistência. Nesse documento ficou comprovado que o território de Tatajuba é composto de aproximadamente $60 \%$ de feições ambientais complexas, caracterizadas como Áreas de Preservação Permanente (APPs); $15 \%$ é área de Domínio da União e $25 \%$ são terrenos sedimentares já em sua maioria ocupados por núcleos populacionais e atividades agrícolas (TERRAMAR, 2003).

Porém, contrariando as diretrizes do Ibama para a

10Para uma análise mais detalhada dessas e de outras medidas tomadas, consultar os Dossiês elaborados pelo Instituto Terramar (2003; 2008) e a síntese histórica elaborada por Mendes (2006, p. 188-192) no bom estudo sobre os conflitos ocorridos em Tatajuba até 2006. Depoimentos e análises mais recentes estão na nossa pesquisa de doutorado (ASSIS, 2012) conservação dos ecossistemas de Tatajuba, no mesmo ano, a Empresa Vitória Régia apresentou em Audiência Pública na comunidade o projeto do Condado Ecológico. Era mais um complexo de turismo e eventos que previa a construção de resorts, parque temático natural e equipamentos de lazer nos 5.275,450 hectares da área conhecida como Costa da Tatajuba que a empresa alegava a propriedade (Figura 2). 0 megaempreendimento projetava a construção de 4.000 unidades habitacionais para a recepção de 15.000 turistas mensais, com investimento estimado de 295,5 milhões de reais (CEARÁ, 2004, p. 291). Mesmo sob o embargo da ação judicial impetrada pela Acomota, o projeto figurava na lista de iniciativa de prioridade da Secretaria de Turismo do Ceará (Setur), inclusive destacado no Prodetur/CE II ${ }^{1}$.

Os empresários usaram de "velhos" argumentos, ratificados pelo Estado, para convencer a comunidade sobre a necessidade do empreendimento, o qual contribuiria para o desenvolvimento local através da melhoria da infraestrutura e a oferta de 22.000 empregos diretos e indiretos (TERRAMAR, 2003; CEARÁ, 2004, p. 296).

Entretanto, na Audiência de apresentação do projeto, o representante da Comissão de Direitos Humanos da OAB (Ordem dos Advogados do Brasil) fez importante advertência à comunidade: "Empresa visa lucro. É fantasia achar que uma empresa vem para cá distribuir riqueza com a comunidade. Todo empreendimento traz também benefícios sociais, dá empregos etc. Mas, fundamentalmente, empresa quer lucro" (TERRAMAR, 2003, p. 19).

E essa máxima capitalista se confirmou nos anos seguintes quando a Acomota continuou com a luta na comunidade e na justiça, forçando os empresários, sequiosos de lucros rápidos, a "abortarem" o empreendimento e a repassarem as terras a um novo grupo ${ }^{12}$ que mudou as estratégias de enfrentamento.

A partir de 2005, com o fim do patrocínio da empresa, as duas novas Associações perderam força e foram desmascaradas na comunidade. 0 novo grupo de acionistas, inclusive, ameaçou processar alguns líderes do Conselho e da Associação de Vila Nova que estavam se beneficiando com a venda de terras em Tatajuba, "às escondidas" dos empresários. Acuados, esses moradores

\footnotetext{
${ }^{11} \mathrm{O}$ Instituto Terramar também denuncia que "[...] dentro da política ambiental adotada pelo governo do estado do Ceará, complexo hoteleiro é considerado 'projeto de interesse social', o que agiliza os trâmites de implantação e funciona como senha de acesso aos licenciamentos ambientais. O EIA/Rima é dispensado, bastando apresentar o RAS - Relatório Ambiental Simplificado. O rigor do controle ambiental dos projetos turístico-hoteleiros fica comprometido, motivo a mais de preocupação das comunidades impactadas (TERRAMAR, 2008, p. 15)

${ }^{12}$ Até o fechamento da pesquisa, a Acomota não sabia ao certo em que mãos estavam os títulos de propriedade das terras de Tatajuba. Sua assessoria jurídica tinha entrado com uma ação para descobrir os "novos proprietários" das terras que
} estavam sendo comercializadas, mesmo sub judice (ASSIS, 2012). 
vêm buscando refúgio na Acomota, justificando que foram enganados pela empresa e desejam se reintegrar à luta coletiva em defesa do território.

Dividida, não só pela geografia ou pela antiga empresa que a ameaçava, a comunidade de Tatajuba prossegue com a luta e outros desafios. Os novos empresários sinalizam o interesse em arrendar aquelas terras para a instalação de usinas eólicas. Tal estratégia imobiliária é crescente em outras praias de Camocim e do litoral do Ceará, pois coaduna a geração de renda mensal com a valorização especulativa das terras, especialmente diante dos investimentos públicos realizados em rodovias e aeroportos no estado.

O crescente número de visitantes encantados com Tatajuba e ali querendo residir também se tornou um problema. A venda de terrenos da praia para turistas estrangeiros aumentou nos anos dos maiores conflitos, facilitando a entrada de novos residentes na comunidade que logo transformaram as moradias em pousadas, associando o ócio ao negócio. Na beira-mar de Tatajuba, já se encontram pousadas de espanhóis e holandeses (Figura 6) que, à revelia da comunidade, continuam expandindo os empreendimentos numa área visivelmente non ædificandi de terrenos de marinha cuja

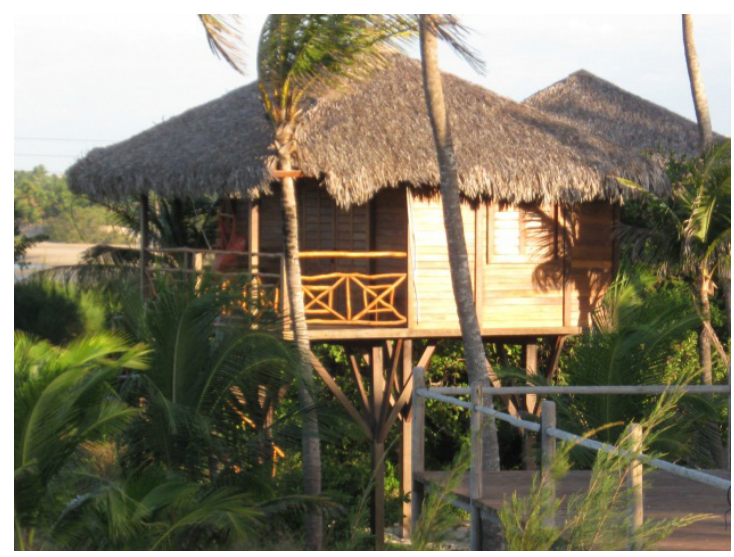

Fonte: Lenilton Assis, 2011.

proteção permanente é "garantida" por diversas leis, federal, estadual e municipal - como é o caso da própria APA da Tatajuba, criada pelo município em 1994.

Porém, na realidade, promotores imobiliários e turistas continuam transgredindo essas leis com estratégias já conhecidas em outras praias cearenses: mesmo sabendo da ilegalidade, vão construindo e "consumando" a apropriação do território, contando com a morosidade da justiça e com os noticiados casos de irregularidades nos licenciamentos ambientais no estado (ACMP, 2008). Quando são notificados, os empreendimentos já são fato de difícil embargo ou ordenamento de demolição. $E$ quando isso ocorre, eles acionam a mesma justiça, já na condição de réus, e exigem uma indenização compensatória pelas benfeitorias realizadas.

Desse jeito, os novos residentes vão ganhando força e território em Tatajuba, colocando-se como mais um desafio para a comunidade conter a especulação imobiliária e o turismo predatório.

Nos últimos anos, a inserção de Tatajuba na rede Tucum e sua articulação a outras redes, como a Turisol e a Redturs, deu mais evidência à luta da comunidade que correu o mundo via internet, recebendo várias moções de apoio, sobretudo de ONGs internacionais que passaram a patrocinar algumas iniciativas para fortalecimento do turismo comunitário.

\begin{abstract}
Nós temos assessoria de várias instituições nacionais e estrangeiras que já trabalham o turismo comunitário em várias partes do Brasil e do mundo. [...] A gente tem parceiros da Suíça, Alemanha e Itália, como a ONG Intervita, que nos mandou um financiamento de 60 mil reais pra gente dá continuidade ao projeto de turismo comunitário. Desses 60 mil, iniciamos a construção dos chalés e uma parte foi tirada pra fazer a nova sede da Associação, comprar computador, instalar internet e ainda ficou um fundo de 3 mil que circula da seguinte maneira: eu estou precisando de 500 reais pra ajeitar meu banheiro, pego o dinheiro e depois fico pagando pra servir a outros associados. 0 projeto dos chalés é pra que cada associado possa construir 2 ou 3 quartos ao lado de suas casas pra receber pessoas, pra dar outro avanço no turismo comunitário [...]. (Liderança da Acomota, 3/7/2010)
\end{abstract}

Adotando princípios da economia solidária, a Acomota conseguiu partilhar e investir os recursos captados na melhoria de alguns quartos que já funcionavam como alojamento, na construção e mobília da nova sede, além 
de iniciar a edificação de seis chalés com técnicas de bioconstrução ${ }^{13}$.

Os chalés já estão em funcionamento, com a oferta de hospedagem simples, acessível e aconchegante (Figura 7).
Os "pacotes" e todo o roteiro da viagem a Tatajuba são comercializados no site da rede Tucum www.tucum. org, que tem links com as redes brasileira e latinoamericana de turismo comunitário. Além da hospedagem com o café da manhã, as demais refeições e o aluguel de buggy também são oferecidos por membros da própria comunidade, demonstrando a viabilidade econômica e a capilaridade social do turismo comunitário.

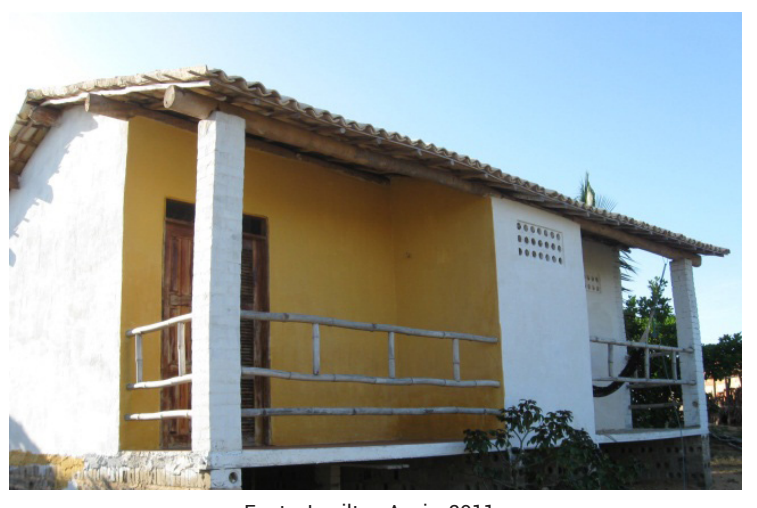

Fonte: Lenilton Assis, 2011.

\section{Conclusão: por que não fortalecer o turismo comunitário} no Ceará?

Mesmo diante de várias experiências positivas de desenvolvimento endógeno, o governo do Ceará insiste em priorizar, nas políticas de turismo, a atração e o financiamento de macroinvestimentos exógenos. Grandes projetos são lançados prometendo "mudar a cara" do turismo estadual, tais como o novo Centro de Eventos e o Acquário Ceará. Com justificativas admissíveis, diga-se de passagem, essas ações, no entanto, reforçam a opção pelo "monodesenvolvimento" ancorado na criação de simulacros para atrair o "de fora", o turista internacional, quando deveriam acontecer, pari passu, beneficiando, sobretudo os "de dentro", as iniciativas locais, a exemplo da rede Tucum.

O governo do estado, ao optar por esta "via de mão única", fica refém dos ânimos de investidores e turistas estrangeiros que oscilam com as flutuações do câmbio e da economia mundial. 0 fortalecimento do turismo comunitário daria ao Ceará mais chances de criar um produto turístico diversificado que é menos suscetível à sazonalidade e às crises econômicas, pois agrada

${ }^{13}$ Técnica usada na construção de casas cujos materiais são naturais da região (terra, bambu, palha, barro etc.) e agridem minimamente o meio ambiente. a todos os gostos e bolsos - tanto os que procuram resorts ou entretenimentos nas grandes cidades quanto os que preferem maior contato com a natureza e a cultura das comunidades tradicionais.

A recente crise econômica mundial tem retraído o fluxo de visitantes estrangeiros ao Nordeste e servido de alerta. 0 complexo hoteleiro da Costa do Sauípe, na Bahia, é outro case de insucesso, apontado por muitos estudiosos como um modelo a não ser seguido na região. Sauípe é um dos maiores empreendimentos brasileiros na área de resorts turísticos que não trouxe nenhuma contribuição para melhorar os indicadores de desenvolvimento do município de Mata de São João, sede do complexo.

Com base numa série histórica de dados estatísticos anteriores e posteriores à implantação do megaempreendimento, Ribeiro (2005) evidencia que não houve melhoria significativa em indicadores como Índice de Desenvolvimento Humano (IDH), Índice de Gini ou Índice de Qualidade de Vida Urbana, dentre outros. O significativo aumento dos fluxos turísticos não propiciou efeito positivo para a qualidade de vida das populações locais. Suas condições de existência ficaram dependendo de um fortalecimento de políticas públicas sociais suplementares. Os investimentos da ordem de meio milhão de dólares voltados para a implantação do megaempreedimento não trouxeram consigo diminuição do processo de exclusão social. (BURSZTYN; BARTHOLO; DELAMARO, 2009, p. 84-85) 
Por isso, ao mudar o foco dos investimentos, o turismo comunitário no Ceará se transformaria em uma política de grande impacto social que melhoraria os serviços básicos das comunidades, diversificaria suas economias, provendo mais capacitações e postos de trabalho, principalmente para mulheres e jovens que são mais vulneráveis à exploração do turismo sexual, ao envolvimento com as drogas, à migração para grandes cidades e para fora do País.

Para tanto, é necessário ao Estado enfrentar (e querer resolver!) o principal problema que aflige as comunidades litorâneas: a questão da propriedade da terra. Sem o devido amparo estatal, as comunidades travam diariamente uma luta desigual com agentes imobiliários, turistas e empresas que avançam loteando terras, construindo equipamentos em áreas sob litígio e até naquelas de proteção ambiental e pertencentes ao Patrimônio da União - como os terrenos de marinha.

E esses problemas se arrastam de governo a governo, com paliativos jurídico-administrativos (audiências públicas, levantamentos, zoneamentos etc.) que não resolvem a questão em definitivo - como é o caso de Tatajuba. Questão esta, vale lembrar, que só ao Estado compete definir, pois dispõe dos mecanismos institucionais e constitucionais para exercer sua função social basilar: zelar pelo bem-estar da sociedade, especialmente dos mais pobres.

Diante da indefinição sobre a propriedade da terra, as comunidades também ficam impossibilitadas de pleitear linhas de crédito estatais (como as do BNDES destinadas aos hotéis para a Copa de 2014), que são facilmente captadas pela iniciativa privada. E tanto a Copa do Mundo quanto os Jogos Olímpicos do Rio, em 2016, provocaram um "refluxo" nas políticas voltadas ao turismo comunitário no Brasil. Desde o Edital de 2008, estas foram cada vez mais suplantadas pelos altos investimentos públicos em infraestrutura para os eventos esportivos, a exemplo da construção de novos estádios de futebol (como a Arena Castelão, em Fortaleza que foi o primeiro inaugurado para a Copa) e de reformas milionárias (como a do Maracanã, que ultrapassou a cifra de 1 bilhão de reais).

Criado em 1992, o Programa de Desenvolvimento do Turismo, seja na sua versão Regional (Prodetur-NE), seja na sua versão atual (Prodetur-Nacional), continua sendo o carro-chefe dos grandes projetos e políticas de turismo no País. Para efeito de comparação, em 2008, quando o turismo comunitário recebeu maior atenção do governo federal, os recursos destinados a esse segmento chegaram a apenas cerca de 11 milhões de reais, enquanto o Prodetur ultrapassou a casa dos 185 milhões (REZENDE, 2011).

Apesar de a presidente Dilma Roussef (2011-2016) ter dado continuidade às políticas de combate à pobreza no País, seu governo também priorizou os macroprojetos do Prodetur e arrefeceu o empoderamento políticoinstitucional adquirido pelo turismo comunitário no Edital de 2008.

Por isso, o turismo comunitário no Brasil caminha a passos lentos e com iniciativas públicas incipientes. No Ceará, onde o apoio institucional ao segmento é ainda mais pontual, as comunidades litorâneas assistem à inauguração de obras que quase nunca beneficiam diretamente seus territórios. A carência de serviços básicos ainda lhes impõe uma quase "imobilidade" em meio às rotas de turismo, onde vias e aeroportos são construídos com dinheiro público para beneficiar, sobretudo, empresários e visitantes ${ }^{14}$.

Em Tatajuba, por exemplo, a mobilidade cotidiana é um desafio constante, com alto custo e risco de vida. Dois veículos particulares passam nas primeiras horas da manhã nas quatro vilas recolhendo a população que, espremida em bancos de madeiras adaptados nas caçambas, é levada à cidade de Camocim para se abastecer no comércio ou de serviços especializados (Figura 8 a seguir).

${ }^{14}$ Após a reforma do Aeroporto Regional de Camocim, está em construção, pelo governo do estado, o Aeroporto Internacional de Jericoacoara. Também foi concluída a Rodovia Estruturante (CE-085), ligando os municípios de Camocim e Jericoacoara à capital Fortaleza e ao vizinho estado do Piauí. 


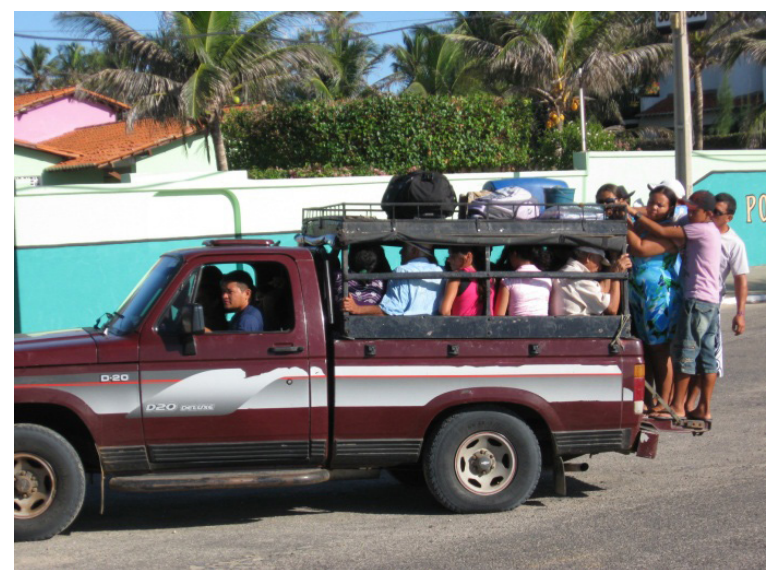

Fonte: Lenilton Assis, 2011.

A passagem de ida e volta custa 12 reais (10 do carro e 2 da balsa), o que representa um custo bastante elevado para o perfil de renda da comunidade. 0 retorno à vila ocorre no final da manhã, quando os carros ficam superlotados de pessoas e mantimentos, com flagrante falta de segurança para percorrerem as areias movediças dos campos de dunas.

Todos esses desafios enfrentados diariamente comprovam que, em plena rota turística entre CamocimJericoacoara, os meios de acesso ao território (tão aclamados para os visitantes!) ainda são muito restritos e difíceis para a comunidade de Tatajuba. Em tempos em que a mobilidade é reverenciada como portadora de maior liberdade, as redes técnicas implantadas no litoral oeste do Ceará mostram também a sua contraface imposta pelo Estado e empresas do setor imobiliárioturístico que redesenham rotas e fluxos, privilegiando as áreas de maior interesse.

Nesse sentido, Raffestin (1993, p. 204) não nos deixa esquecer de que "a rede faz e desfaz as prisões do espaço, tornado território: tanto liberta quanto aprisiona. É o porquê de ela ser o 'instrumento', por excelência, do poder".

Demanda antiga da comunidade, a melhoria de acesso e de opções de transporte mais barato é sempre apontada nos planos municipais e relembrada durante os pleitos eleitorais. Entretanto, no cotidiano da população, a mobilidade é mais um direito cerceado pelo Poder Público que se soma à falta da garantia do território e do apoio às iniciativas endógenas de desenvolvimento. Tais desafios motivam a comunidade a lutar por esses direitos e a inovar com propostas afirmativas de sustentabilidade, a exemplo da rede Tucum. 


\section{Referências}

ACMP. (2008) Associação Cearense do Ministério Público. Presos dirigentes do Ibama, Semace e Semam. Disponível em: <https://amp-ce.jusbrasil.com.br/noticias/156116/presos-dirigentes-do-ibama-semace-e-semam> Acesso em: 21 out. 2010.

ARAÚJJ, T. B. (2000) Ensaios sobre o desenvolvimento brasileiro: heranças e urgências. Rio de Janeiro: Revan/Fase.

(2008) O contexto mundial e as diversas visões de territórios e de desenvolvimento regional sustentável. In: MIRANDA, C. et al. Articulação de políticas públicas e atores sociais. Brasília: IICA, p. 15-28.

ASSIS, L. F. (2012) Entre o turismo e o imobiliário: velhos e novos usos das segundas residências sob o enfoque da multiterritorialidade - Camocim/CE. 278 f. Tese (Doutorado em Geografia Humana), Departamento de Geografia, Universidade de São Paulo. Disponível em: <http://www.teses.usp.br/teses/disponiveis/8/8136/tde-23052012220752/> Acesso em: 21 nov. 2012.

BRASIL. (2001) Instituto Brasileiro do Meio Ambiente e dos Recursos Naturais Renováveis - Ibama. Laudo Ambiental da Localidade de Tatajuba - Camocim/CE. Fortaleza: Ibama, Gerência Executiva do Ibama-CE. 55 p.

(2008) Ministério do Turismo. Edital MTur n. 001/2008. Seleção de Propostas de Projetos para Apoio às Iniciativas de Turismo de Base Comunitária. Brasília: Ministério do Turismo.

(2010) Ministério do Turismo. Dinâmica e diversidade do turismo de base comunitária: desafio para a formulação de política pública. Brasília: Ministério do Turismo.

BURSZTYN, I.; BARTHOLO, R.; DELAMARO, M. (2009) Turismo para quem? Sobre caminhos de desenvolvimento e alternativas para o turismo no Brasil. In: BARTHOLO, R.; SANSOLO, D. G.; BURSZTYN, I. (orgs.). Turismo de base comunitária: experiências brasileiras. Rio de Janeiro: Letra e imagem, p. 76-91.

CEARÁ. (2004) Secretaria de Turismo - Setur/CE. Prodetur/NE II. PDITS - Plano de Desenvolvimento Integrado do Turismo Sustentável do Polo Ceará Costa do Sol. Fortaleza: Ruschmann Consultores. Disponível em: <http://www.bnb. gov.br/content/aplicacao/prodetur/downloads/gerados/pdits_ceara.asp>. Acesso em: 25 nov. 2004

CORIOLANO, L. N. M. T. (2009) O turismo comunitário no Nordeste brasileiro. In: BARTHOLO, R.; SANSOLO, D. G.; BURSZTYN, I. (orgs.). Turismo de base comunitária: experiências brasileiras. Rio de Janeiro: Letra e imagem, p. 277288.

HAESBAERT, R. (2006) O mito da desterritorialização: do "fim dos territórios" à multiterritorialidade. 2. ed. Rio de Janeiro: Bertrand Brasil.

(2009) Dilema de conceitos: espaço-território e contenção territorial. In: SAQUET, M. A.; SPOSITO, E. S. (orgs.). Territórios e territorialidades: teorias, processos e conflitos. São Paulo: Expressão Popular, p. 95-120.

IRVING, M. A. (2009) Reinventando a reflexão sobre o turismo de base comunitária. In: BARTHOLO, R.; SANSOLO, D. G.; BURSZTYN, I. (orgs.). Turismo de base comunitária: experiências brasileiras. Rio de Janeiro: Letra e imagem, p. 108-121.

MENDES, E. G. (2006) De espaço comunitário a espaço do turismo: conflitos e resistências em Tatajuba, Camocim Ceará. 192 f. Dissertação (Mestrado em Geografia), Universidade Estadual do Ceará, Fortaleza, MAG.

RAFFESTIN, C. (1993) Por uma geografia do poder. São Paulo: Ática.

REZENDE, R. O. (2011) Turismo de base comunitária, política pública e efeitos sobre o local: o caso do projeto "Um Vale de Verdade", Pirenópolis (GO). 241 f. Dissertação (Mestrado em Estudos Populacionais e Pesquisas Sociais), Escola Nacional de Ciências Estatísticas (ENCE), IBGE, Rio de Janeiro.

RODRIGUES, A. B. (2008) Turismo e fortalecimento de microeconomias locais - oportunidades de inserção social em bases comunitárias. In: BURNE, S. M.; DACHARY, A. C. (orgs.). Turismo y desarrollo: crecimiento y pobreza. Puerto Val- 
larta: Ed. Universidad de Guadalajara, Universidad de Buenos Aires, Universidad Nacional de Mar del Plata, p. 37-46.

SILVA, K. T. P.; TEIXEIRA, R. C.; RAMIRO, B. S. (2009) Fomento ao turismo de base comunitária: a experiência do Ministério do Turismo. In: BARTHOLO, R.; SANSOLO, D. G.; BURSZTYN, I. (orgs.). Turismo de base comunitária: experiências brasileiras. Rio de Janeiro: Letra e imagem, p. 359-368.

TERRAMAR. (2003) Dossiê do Conflito Fundiário na Comunidade de Tatajuba: 2001-2003. Fortaleza: Instituto Terramar.

(2008) Dossiê Ambiental: degradações, conflitos e crimes ambientais em Fortaleza e no estado do Ceará. Fortaleza: Instituto Terramar 